\title{
Progress in Chemical and Biochemical Research
}

Journal homepage: www.pcbiochemres.com

Short Communication

\section{Risk Management in Information Technology}

\section{Amir Samimi}

Ph.D. of Science in Chemical engineering, Risk Specialist of Oil and Gas Refinery Company, Iran

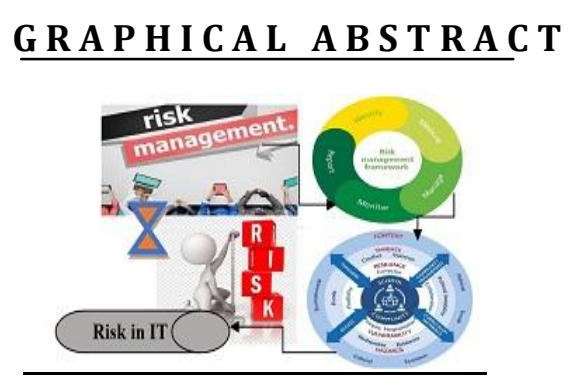

A R T I C L E IN F O

\section{Article history:}

Submitted: 2020-01-12

Revised: 2020-04-14

Accepted: 2020-04-23

Published: 2020-04-24

Manuscript ID: PCBR-2004-1090

\section{K E Y W O R D S}

Industry,

Information and Technology,

Organization,

Risk Management,

Telecommunication Networks,

\section{A B S T R A C T}

This study has examined risk management planning in the field of Information Technology in industrial companies. Today, information is considered a valuable factor along with other factors of production. The rapid growth of the Internet and organizational databases in recent decades has intensified the process of moderating business behavior and its relationship to markets. This situation and its possible developments pose several challenges to our ability to design and deliver information systems. Most managers of organizations have become aware of the importance of using this technology in increasing the efficiency and effectiveness of organizations and greater customer satisfaction. In addition to failing to meet the projected benefits, it is likely that the failure of this IT will not be limited to the financial and economic disadvantages of managing the subtleties of project execution and may continue to IT as long as an organization fails. Regarding the process of risk management or information security risks, there are methods and methodologies which define steps to evaluation process and risk treatment according to the considered approach. But in most of these methods, some basic principles and concepts are considered the same.

\section{INTRODUCTION}

For decades, the value and importance of information systems and information and communication technology has played a decisive and pervasive role in corporate business. With rapid technological change, globalization and the expansion of efficient domain are among the requirements for achieving competitive advantage.

Information technology in the fields of hardware, software, volume and data type and telecommunication networks is rapidly evolving and changing [1-3] . This situation and its possible developments pose several challenges to our ability to design and deliver information systems. However, for many organizations information systems, information and communication technology in general still play an innovative role in market performance and communication with those involved. This means that the acceptance process has become a possible objectivity of the decision-making process or management issues. Motivation for innovation arises in an organization when decision makers consider functional gaps or realize that the current state of the organization is unsatisfactory. In the information security risk management process, the organization's risk management strategy must be accurately anticipated. However, the precondition for going to discussion is having a correct understanding of the risk concept and be aware of the importance of recognizing and managing it [느으.

\footnotetext{
* Corresponding author: Amir Samimi

Tel number: +989134027005, E-mail: amirsamimi1161@gmail.com 


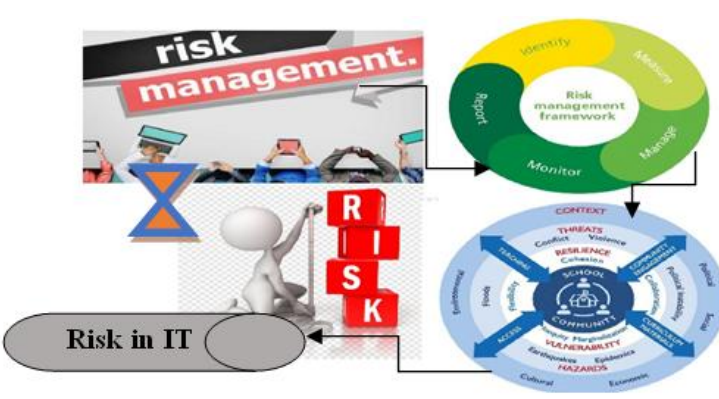

Fig. 1: Information Security Risk Management Process in Industrial Companies

As you can see in Fig.1, the information security risk management process consists of five steps which two main of it are risk assessment and risk treatment. However, the next three steps, communication, monitoring and risk review are also inseparable components of this process.

In Fig.1 the information security risk management process in industrial companies is shown. Risk management is an important and necessary management that makes accurate decisions based on the level of risk and risk and is used in most parts of the world by IT executives. Due to its inherent complexity, the IT business is prone to risk, and therefore it is necessary to manage risk to protect projects as much as possible from damage caused by events. The concept of risk management also defines a codified process for identifying and evaluating risks and selecting management strategies and how to deal with them. Admittedly, the risk cannot be completely eliminated. And in the face of any risk, options will not come out of a set of four distinct approaches: risk can be mitigated by reducing the likelihood of its occurrence through continuous control and monitoring of occurrence conditions and strengthening vulnerability points; Replaced one risk with another. Technological recovery and the process have a tangible role in achieving quality and performance goals. Detecting these improvements which increases the quality of the organization level is a crucial process for the performance of an individual firm. From a strategic point of view, the success of management innovation processes depends on competitive efforts. These efforts may include in-depth knowledge of technological advances and adequate analysis of network advantages []]. This means that managers need to consider technologies that are necessarily combined with creating high levels of knowledge as well as improving quality for the reasons provided. In order to make better use of managerial resources, the development and acceptance of new technologies must be related to cost and management effectiveness evidence. However, recent major advances in the implementation and promotion of ICT assessment, the development of these technologies has had little effect on many organizations. In the process of information security risk management, after identification, risk analysis is considered as risk assessment. The manner and strategy of dealing with the identified risks and the risk assessment outcome should be determined. In general, it can be said that today information is considered as a valuable factor along with other factors of production. With rapid technological change, globalization and the expansion of efficient domain are among the requirements for achieving competitive advantage. In this study, we conclude that identifying and managing the risks observed before and during the implementation of IT projects plays a key role. Risk management should be a preventative activity []. Then to be successful, you need to use a standard method. Using a standard framework and method will help managers avoid mistakes such as losing opportunities and threats and spending a lot of time and resources. And finally, success in identifying and reducing project risks can reveal technical and non-technical risks and problems for key managers and stakeholders, focus resources on high-risk areas and while putting risks within reasonable limits, manage them in an accurate and measurable way.

Risk Analysis: Systematic use of information to identify and estimate risk.

Risk Evaluation: It is a process that helps determine the importance of the risk to the organization. This is done by comparing the estimated risk, the previous step output, with the organization's risk criteria. 
In IT-based organizations, we have two types of information management, or CIOs: infrastructure management and organizational meta-structures, and strategic management and strategic thinkers, the latter of which is more successful in risk management because it is more tangible with business. For example, instead of talking about "daily zero-point threats", they value the potential for losing business as an accident, or instead of talking about current day-to-day operations, they focus more on losing customers or users in the future. Losing creativity in employees with the goal of sharing their information to manage risk is also more important than discussing IT controls and standards. Therefore, using a common and understandable language to ensure profitability in business is one of the first basic steps that risk management takes. Calculating the risk from top to middle and low is one of the next steps to reassure shareholders that virtual scenarios can be used to understand the risks of data loss. The type of risk management results based on statistics are worth noting and follow the middle level goals.

Risk Treatment: At this stage, the organization must determine its strategy and plan for dealing with unacceptable risks. The most important output of this section is the Risk Treatment Plan (RTP) [9].

Risk Communication: The issue of communication should be considered as an important element in all stages of the risk management process. In fact, at each stage of the process, effective communication must be established between risk beneficiaries, consultants, senior management, asset owners, risk holders, or other stakeholders.

Risk Control and Monitoring: The main focus in this section is on controlling and pursuing risk management plans. The status of RTP projects should be continuously monitored in terms of timing, impact, quality and optimization and appropriate action should be taken to correct the cases or to take corrective action [1]].

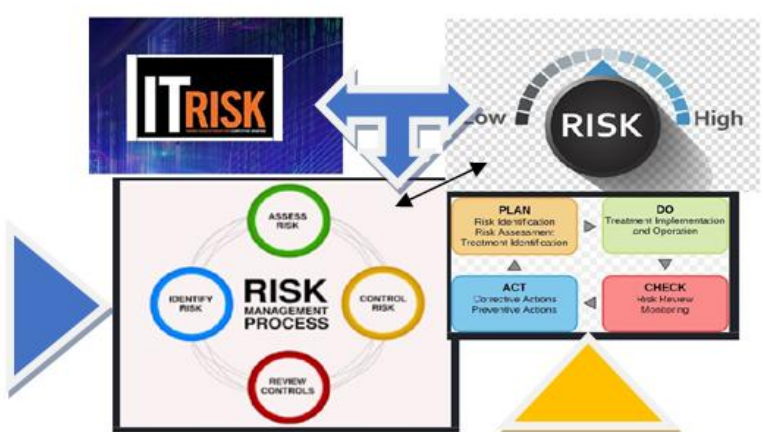

Fig. 2. IT Risk Process

Risk Review: A project's view of risk management (as a process with a start and end time) is not correct and the cyclical nature of this process indicates that this process is not a step and the nature of continuous improvement in it. In fact, the introduced activities must be repeated in the specified time intervals and the results and experiences obtained from each iteration step be used as input and feedback in the new step. The intervals for risk review should also be performed according to the conditions of the organization and within the maximum intervals of one year. In Fig.2 IT resk is shown.

\section{Strengthen Risk Management Programs in IT}

The electronic world requires a common chapter between human beings and technology, and the key to achieving successful results depends on managing evolution to better guide the organization, employees, and electronic commerce. Emphasis on entrepreneurship, special attention to creativity and innovation, guidance and leadership based on technical principles, effective culture building and the development of communication skills are the main features of era.com. An era that has severely challenged management and leadership [11]. In Russia, given the prosperity of the economy, there is a willingness to spend a lot of money on IT. Every day, more and more project managers are realizing the need to use IT systems in which the need to use risk management becomes more apparent [12]. The risk management process can be clearly defined as the actual and necessary steps taken for the successful implementation of IT projects. Given that the market is developing and 
there is a demand for IT services, sellers of these services must ensure the high quality of these services by controlling and calculating possible risks. The following are some of the risks that often stand in the way of IT development: Lack of understanding of the shareholder's role and the position of information technology, doubts about the repayment of IT projects, low level of readiness of people to use new technologies and in rare cases, poor infrastructure. The new information systems offer a set of comprehensive and combined solutions and methods of application that typically require significant investment from companies. Information technology systems are a complete set of programmatic and technical facilities and tools that are used to analyze, protect and process data [13-16]. Analytical tools which are part of IT systems, make it possible to process large amounts of information at high speeds and perform corrective actions based on the results obtained.

Information technology risk management is completely technology-oriented and deals with software, hardware, information and data, but dealing with people is not necessarily completely technical. Because auditors, business leaders, and legal groups also face risk management in this regard and are somehow accountable. Therefore, there is a close relationship between IT and non-IT in this area. Identifying the project goal is another practical step for proper risk management in information technology. In the risk methods section, identification, characterization, and threat assessment should be mentioned. Then the exact amount of tangible and real threats is estimated and then the risk is defined and explained. Finally, there are ways to reduce risk and risk. The main goal of continuous development and continuous strengthening of information security in the field of information technology is based on risk management.

\section{Develop Strategies for Ensuring Uninterrupted Activity}

Whether a company operates in the healthcare, pharmaceutical or financial sectors, or in any other area, strategies must be established by the facility management and information technology management to ensure that the company's business continues uninterrupted. There is no doubt that failure in communication, telecommunications and IT, as a vital artery of a business will be the main reason for the impact and consequently its failure.

\section{CONCLUSION}

Regarding the process of risk management or information security risks, there are many methods and methodologies, each of which, according to their approach, defines steps to perform the process of risk assessment and coping. But in most of these methods, some basic principles and concepts are considered the same. Despite extensive research in this regard, unfortunately for various reasons, including security issues for governmental and non-governmental organizations or the direct relationship of the relevant field with their interests, clear and useful information on how to implement and prioritize the implementation of a system has not been done over the years until today. Procurement of communications, technology and information systems is a fundamental need to support competitive strategies and improve the service level of organizations. Organizations set up projects to deliver business solutions using information technology systems. Each project is unique and can be identified with specific goals, specific start and end dates and a unique set of activities, resources (capital, individuals, and equipment), a separate organizational structure and the need for management. It can be concluded that the tolerance strategy is usually used for those risks that have high effects and losses and are more likely to occur, or a risk transfer strategy can be used for those risks that have many effects and losses but are unlikely to occur. On the other hand, the termination strategy can be used for those risks that have low effects and losses and are more likely to occur. Also, a risk mitigation strategy can be used for those risks that have low effects and losses and are unlikely to occur. One of the challenges that IT project managers face is that the required resources for a particular activity may be scarce.

\section{CONFLICTS OF INTEREST}

No conflict of interest was declared by the author 


\section{REFERENCES}

[1] M.T. Fard and F. Samadi, Effective factors on the implementation of Green IT initiatives in organizations with emphasis on virtualization. Iranian journal of management sciences, 9 (2014) 88-112.

[2] A. Samimi, S. Zarinabadi and M. Setoudeh, Safety and Inspection for Preventing Fouling in Oil Exchangers. International Journal of Basic and Applied science, Indonesia, (2012) 429-434.

[3] O.V. LENKOVA, Risk management of oil and gas company in terms of strategic transformations. Risk management, 39 (2018) 30.

[4] A. Domnikov, G. Chebotareva and M. Khodorovsky, Systematic approach to diagnosis lending risks in project finance. Audit and Finance analyses, 2 (2013) 114-119.

[5] A. Samimi, S. Zarinabadi, A. Bozorgian, A. Amosoltani, M.S. Tarkesh Esfahani and K. Kavousi, Advances of Membrane Technology in Acid Gas Removal in Industries. Progress in Chemical and Biochemical Research, (2020) 4654.

[6] D.A. Yuryevich, K.M. Yakovlevich and K.P. Mikhaylovich, Optimization of finances into regional energy. Экономика региона, (2014)

[7] D. Mohammadnazar and A. Samimi, Nessacities of Studying HSE Management Position and Role in Iran Oil Industry. Journal of Chemical Reviews, 1 (2019) 252-259.

[8] D. Osabutey, G. Obro-Adibo, W. Agbodohu and P. Kumi, Analysis of risk management practices in the oil and gas industry in Ghana. Case study of Tema Oil Refinery (TOR). European journal of business and management, 5 (2013)
[9] A. Slaughter, P. Zonneveld and T. Shattuck, Refining at risk: Securing downstream assets from cybersecurity threats. Deloitte Insights, New York, NY, USA, Tech. Rep., Nov, (2017)

[10] A. Trujillo-Ponce, R. Samaniego-Medina and C. Cardone-Riportella, Examining what best explains corporate credit risk: accounting-based versus market-based models. Journal of Business Economics and Management, 15 (2014) 253276.

[11] A. Domnikov, P. Khomenko and G. Chebotareva, A risk-oriented approach to capital management at a power generation company in Russia. WIT Transactions on Ecology and the Environment, 1 (2014) 13-24.

[12] V.V. Plenkina, A. Taubayev and O.V. Lenkova, Management tools of cost controlling at the gas transportation enterprise. The Journal of Internet Banking and Commerce, (2016)

[13] O. Vasicek, Credit portfolio models: Loan portfolio value. RISK-LONDON-RISK MAGAZINE LIMITED-, 15 (2002) 160-162.

[14] M. Gürtler and D. Heithecker. (2005), Working Paper Series.

[15] J.m. Pollock, Risk management for black swan risks: planning for nuclear catastrophe, fracking problems, and other environmental disasters. conn. ins. lj, 1 (2008) 2-3.

[16] A. Domnikov, G. Chebotareva, P. Khomenko and M. Khodorovsky, Risk-oriented approach to long-term sustainability management for oil and gas companies in the course of implementation of investment projects. WIT Transactions on Ecology and the Environment, 192 (2015) 275284.

\section{HOW TO CITE THIS ARTICLE}

Samimi. A, Risk Management in Information Technology, Prog. Chem. Biochem. Res. 2020 3(2), 130-134.

DOI: $10.33945 /$ SAMI/PCBR.2020.2.6

URL: http://www.pcbiochemres.com/article_106614.html 